\title{
Ophthalmosaurian (Ichthyosauria) records from the Aalenian-Bajocian of Patagonia (Argentina): an overview
}

\author{
MARTA S. FERNÁNDEZ*† \& MARIANELLA TALEVI \\ *División Palaeontología Vertebrados, Museo de La Plata, Paseo del Bosque s/n, \\ 1900 La Plata, Argentina. CONICET \\ $\ddagger$ †nstituto de Investigación en Paleobiología y Geología, Universidad Nacional de Río Negro, \\ 8332 General Roca, Río Negro, Argentina. CONICET
}

(Received 12 September 2012; accepted 11 January 2013)

\begin{abstract}
The oldest ophthalmosaurian records worldwide have been recovered from the AalenianBajocian boundary of the Neuquén Basin in Central-West Argentina (Mendoza and Neuquén provinces). Although scarce, they document a poorly known period in the evolutionary history of parvipelvian ichthyosaurs. In this contribution we present updated information on these fossils, including a phylogenetic analysis, and a redescription of 'Stenopterygius grandis' Cabrera, 1939. Patagonian ichthyosaur occurrences indicate that during the Bajocian the Neuquén Basin palaeogulf, on the southern margins of the Palaeopacific Ocean, was inhabited by at least three morphologically discrete taxa: the slender Stenopterygius cayi, robust ophthalmosaurian Mollesaurus periallus and another indeterminate ichthyosaurian. Rib bone tissue structure indicates that rib cages of Bajocian ichthyosaurs included forms with dense rib microstructure (Mollesaurus) and forms with an 'osteoporotic-like' pattern (Stenopterygius cayi).
\end{abstract}

Keywords: Mollesaurus, 'Stenopterygius grandis', Middle Jurassic, Neuquén Basin, Argentina.

\section{Introduction}

Ichthyosaurs were one of the main predators in the oceans all over the world during most of the Mesozoic (Massare, 1987). Advanced parvipelvian ichthyosaurs were the first tetrapods to evolve a fish-shaped body profile (Motani, 2005) and, based on the profound morphological modifications of their body plan, are the paradigm of marine adaptation among sauropsids. Parvipelvian evolutionary history spans the Late Triassic up to the Cenomanian-Turonian boundary, when ichthyosaurs became extinct (Bardet 1994; Fischer et al. 2011a). In recent years, knowledge of advanced parvipelvians, termed ophthalmosaurians (Opthalmosauria: Motani, 1999) has increased, triggered by new discoveries and the re-examination of historical collections. Indeed, after publication of the comprehensive handbook of Ichthyopterygia (McGowan \& Motani, 2003), a number of ophthalmosaurian monotypic genera have been erected: Arthropterygius Maxwell, 2010; Athabascasaurus Druckenmiller \& Maxwell, 2010; Sveltonectes Fischer et al. 2011b; Acamptonectes Fischer et al. 2012; Cryopterygius Druckenmiller et al. 2012; and Palvennia Druckenmiller et al. 2012.

Although there is a consensus as to the basic phylogenetic relationships among major groups, including the monophyly of derived ichthyosaurs (the parvipelvian clade of Motani 1999), the affinities of Ophthalmosauria are still controversial. While consistently found as a well-supported clade including

$\dagger$ Author for correspondence: martafer@fcnym.unlp.edu.ar all Callovian and post-Callovian ichthyosaurs, two different Early Jurassic taxa have been proposed as ophthalmosaurian sister taxa: Stenopterygius (Maisch \& Matzke, 2000; Sander, 2000; Druckenmiller \& Maxwell, 2010; Fischer et al. 2011b, 2012; Maxwell, Fernández \& Schoch, 2012) or Ichthyosaurus (Motani, 1999; Thorne, Ruta \& Benton, 2011). Internal topology of the Ophthalmosauria clade is even more contentious, and up to the present has been returned as weakly supported in all analyses.

Examination of parvipelvian topologies combined with the stratigraphic occurrence of taxa depicts a gap in the record from the Aalenian up to the Callovian, comprising most of the Middle Jurassic (Fernández, 2003; McGowan \& Motani, 2003). This gap is interrupted by three taxa, Stenopterygius aaleniensis Maxwell, Fernández \& Schoch (2012), S. cayi (Fernández, 1994) and the ophthalmosaurian Mollesaurus periallus Fernández, 1999. Stenopterygius aaleniensis was recovered from the Aalenian of southwestern Germany, while $M$. periallus and $S$. cayi were recovered from the lower Bajocian Los Molles Formation, which crops out in the Neuquén Basin (Argentina). Mollesaurus periallus is of particular interest as it represents the oldest ophthalmosaurian material identifiable to species level, and it has not been revised since its original description (Fernández, 1999). The only other coeval ophthalmosaurian fossil is a fragment of a forefin from the Aalenian-Bajocian boundary of Northwest Patagonia (Fernández, 2003), which represents the earliest ophthalmosaurian 
recorded worldwide. Although not abundant, these remains are significant because they document the earliest stage in the evolutionary history of the ophthalmosaurian clade. The main aim of this contribution is, therefore, to present the first detailed description of Mollesaurus, as well as update information on a second poorly known taxon from the early Middle Jurassic of Patagonia: 'Stenopterygius grandis' Cabrera, 1939.

Institutional abbreviations. MLP - Museo de La Plata, División Paleontología Vertebrados, La Plata, Argentina; MOZ - Museo Prof. P. Olsacher, Zapala, Argentina.

\section{Historical overview}

The first Middle Jurassic ichthyosaur discovered in the Neuquén Basin (Central-West Argentina) corresponds to a fragment of rostrum, MLP 39-VII-22 , found during a geological survey at Sierra de Chacaico (Fernández, 1943). MLP 39-VII-2-2 was recovered from sediments belonging to the Emileia giebeli ammonite zone in the Los Molles Formation, an early Bajocian unit (Westermann \& Riccardi, 1979) that crops out at Charahuilla Creek, Sierra de Chacaico, Neuquén province, Argentina. Based upon this rostrum, Cabrera (1939) erected the new species Stenopterygius grandis. Since then, MLP 39-VII-22 has been illustrated and/or mentioned (Fernández, 2007) but never specifically revised. In 1984, a geological commission of Yacimientos Petrolíferos Fiscales of Argentina recovered a fragment of an ichthyosaur forefin (MLP 92-III-2-1) from sediments belonging to the Puchenquia malarguensis ammonite zone (Aalenian-Bajocian boundary; Riccardi, 2008) of the Los Molles Formation at Quebrada Remoredo, Sierra de Reyes, Mendoza province, Argentina. This forefin was described as Ophthalmosauria indet. by Fernández (2003). Spalleti, Gasparini \& Fernández (1994), when analysing the transition between the Middle Jurassic Los Molles and Lajas formations in the southeast of the Neuquén Basin (Chacaico Sur), mentioned and illustrated a marine reptile assemblage recovered from sediments belonging to the Emileia giebeli ammonite zone at the top of the Los Molles Formation. These remains included the pliosaur Maresaurus coccai Gasparini, 1997, a trunk vertebra of a thalattosuchian crocodiliform, and two ichthyosaurs: MOZ 5803, initially described as a new genus and species Chacaicosaurus cayi Fernández, 1994, later reassigned to the genus Stenopterygius (Fernández, 2007); and MOZ 2282, identified as aff. Ophthalmosaurus by Spalletti, Gasparini \& Fernández, 1994, and then referred to Mollesaurus periallus by Fernández (1999). The phylogenetic relationships of ichthyosaurs were poorly known at that time and there were few contributions dealing with this issue (Mazin, 1982; Godefroit, 1993; Dal Sasso \& Pinna, 1996). A preliminary phylogenetic analysis of Mollesaurus placed it as the sister taxon to Ophthalmosaurus
(Fernández, 1999). However, in the same year, Motani (1999) published an exhaustive phylogeny of Ichthyopterygia and defined the clade Ophthalmosauria, including all Callovian and stratigraphically later forms, nested within a broader Thunnosauria. Since this contribution, most systematic revisions include Mollesaurus as a valid taxon, and all phylogenetic assessments return it within the Ophthalmosauria (Druckenmiller \& Maxwell, 2010; Maxwell, 2010; Fischer et al. 2011b, 2012). By contrast, Maisch \& Matzke (2000) and Maisch (2010) considered the name Mollesaurus as a junior synonym of Ophthalmosaurus, and Sander (2000) did not include it within his evaluation of ichthyosaurian diversity.

Although Mollesaurus is consistently nested within the Ophthalmosauria, its phylogenetic position within this clade is not clear. Maxwell (2010) described Mollesaurus as forming a basal polytomy within ophthalmosaurians. This arrangement was resolved in an analysis by Druckenmiller \& Maxwell (2010), and Mollesaurus is described as more derived than the Aegirosaurus leptospondylus + Ophthalmosaurus icenicus clade, and the sister taxon of Athabascasaurus chrisorum + Brachypterygius extremus + Arthropterygius chrisorum + Caypullisaurus bonapartei + Platypterygius hercynicus + P. platydactylus $+P$. australis, and Maiaspondylus lindoe $+P$. americanus. However, node supports in these analyses were universally low. A phylogenetic analysis of the ophthalmosaurians by Fischer et al. (2011b) placed Mollesaurus in an even more derivative position than Druckenmiller \& Maxwell (2010), their strict consensus topology depicting it as the sister taxon of Aegirosaurus + Sveltonectes, although node support was again weak $(<50 \%)$. This topology was revised in a recent analysis (Fischer et al. 2012) that included the new genus Acamptonectes, and resulted in a single mostparsimonious tree with Mollesaurus recovered as the sister lineage to Ophthalmosaurus icenicus $+O$. natans + Acamptonectes densus.

\section{Systematic palaeontology}

Order ICHTHYOSAURIA de Blainville, 1835

OPHTHALMOSAURIA sensu Motani, 1999

Genus Mollesaurus Fernández, 1999

Mollesaurus periallus Fernández, 1999

Figures 1-3

2000 Ophthalmosaurus periallus; Maisch \& Matzke, p. 91, nov. comb.

2010 Ophthalmosaurus periallus; Maisch, p. 153

2010 Mollesaurus periallus; Druckenmiller \& Maxwell

2012 Mollesaurus periallus; Fischer, et al., fig. 6

Holotype. MOZ 2282, a skull with articulated vertebral column and ribs.

Type locality and horizon. Chacaico Sur, Neuquén province, Argentina. Emileia giebeli ammonite zone of the Los Molles Formation, early Bajocian (Westermann \& Riccardi, 1979). 


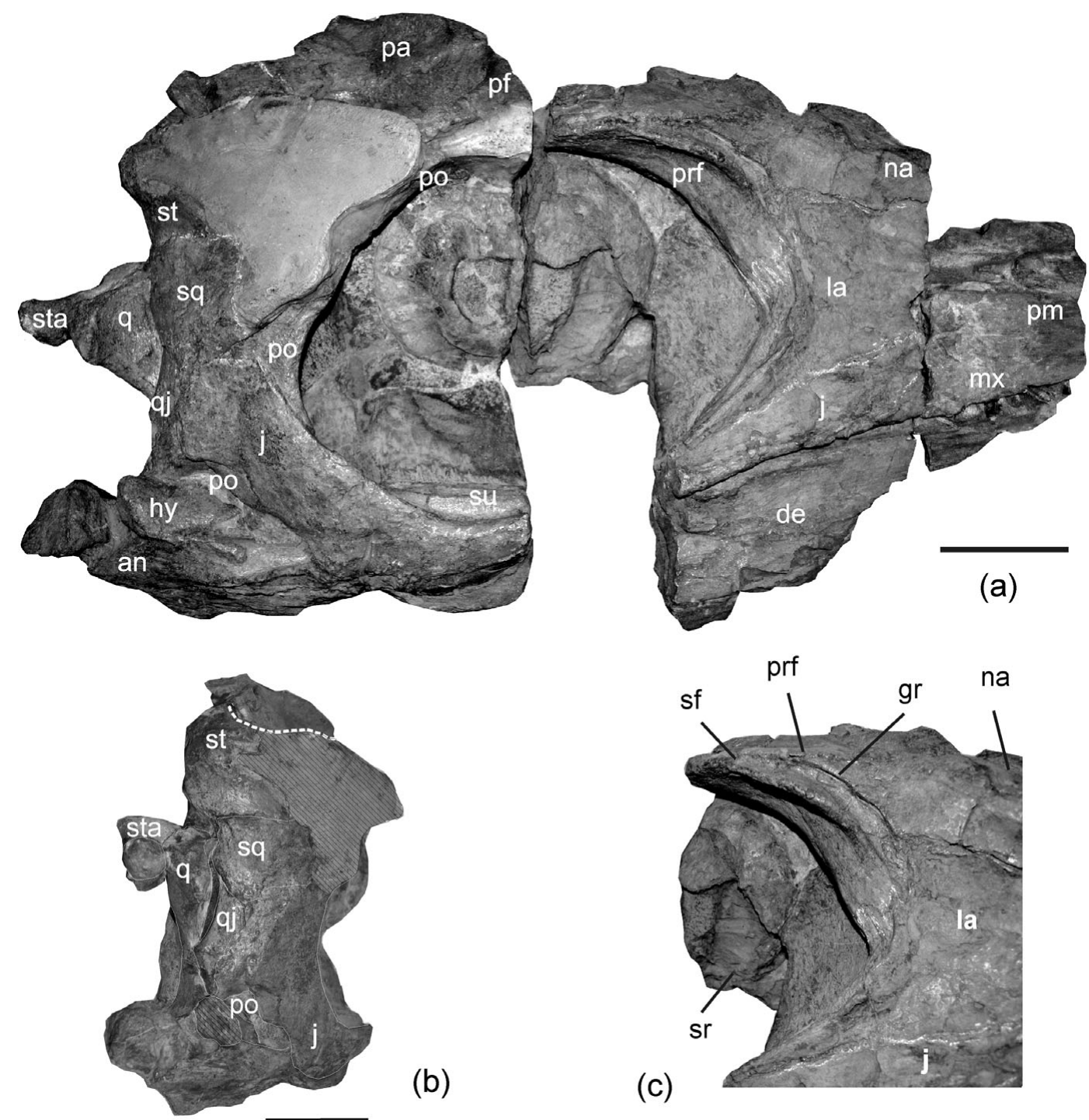

Figure 1. Mollesaurus periallus (MOZ 2282). (a) Skull in lateral view; (b) posterior view; (c) detail of the anterior orbital margin in lateral and slightly anterior view. Anatomical abbreviations: an - angular; de - dentary; gr - groove; hy - hyomandibular element; $j$ - jugal; la - lacrimal; mx - maxilla; na - nasal; pa - parietal; pf - postfrontal; pm - premaxilla; po - postorbital; prf - prefrontal; q - quadrate; qj - quadratojugal; sf - supraorbital flange; sq - squamosal; sr - sclerotic ring; st - supratemporal; sta - stapes; su surangular. Scale bars $=10 \mathrm{~cm}(\mathrm{a}, \mathrm{b})$. (c) is not to scale.

Emended diagnosis. Ophthalmosaurian ichthyosaur characterized by the following combination of characters: broad premaxilla-lacrimal contact ventral to the external naris; reduced exposure of the maxilla in lateral view; large orbit with a strong crest on its anterior margin*; postorbital region of the skull broad; squamosal subquadrangular in outline and broadly exposed in lateral view; basioccipital condyle not clearly offset from the extracondylar area; extracondylar area reduced; deep anterodorsal fossa on the basioccipital*; palatines reaching the subtemporal fenestra; trunk ribs with sharp crests on their dorsal edge*; small teeth with subtle striation on the labial surface. Asterisk $\left(^{*}\right)$ denotes autapomorphies among ophthalmosaurians.

\section{Description}

General remarks. The Mollesaurus periallus holotype is an articulated skeleton recovered within a single concretion containing the skull (Fig. 1a) and nine other smaller blocks including parts of the vertebral column and associated ribs (Fig. 3a). The main block bearing the skull was broken into three parts during extraction and exposes the skull and mandible in right lateral view. The braincase and palatal elements have been completely extracted from the rock. The anteriormost part of the rostrum was not preserved. The most conspicuous features of the skull are its small teeth, a broad postorbital region and the enlarged orbit with a strong crest on its anterior margin. The diameter of the eye measured from the sclerotic ring occupied only $42 \%$ of the orbital area (Fernández et al. 2005). Articulated presacral vertebrae and ribs, a clavicle and a proximal fragment of a scapula were also excavated. None of the fins or other girdle elements could be located. The most conspicuous features of the postcranium are the macro- and microphology of the ribcage. 


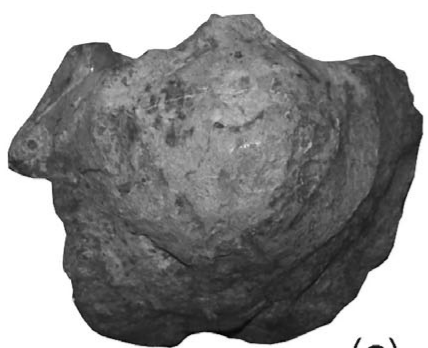

(a)

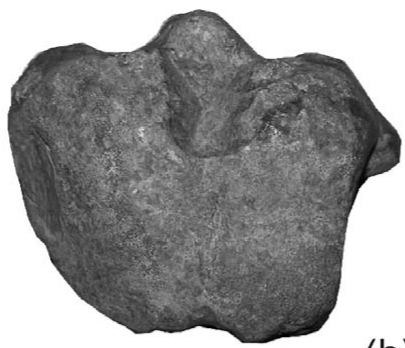

(b)

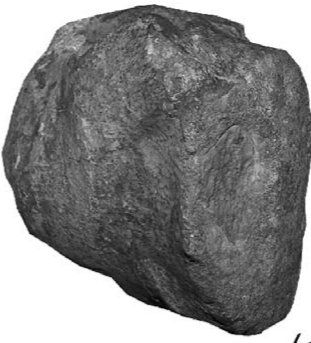

(c)

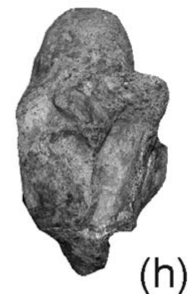

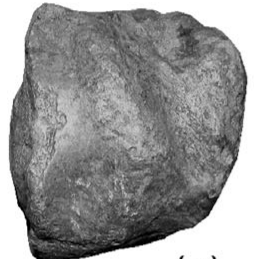

(e) (h)

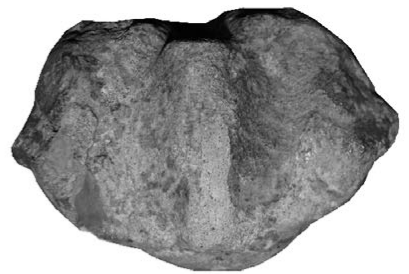

(d)

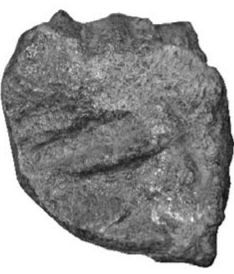

(f)

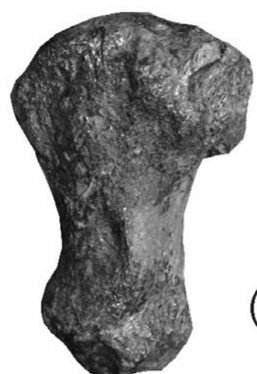

(g)

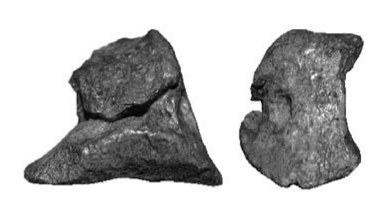

(i)

(j)
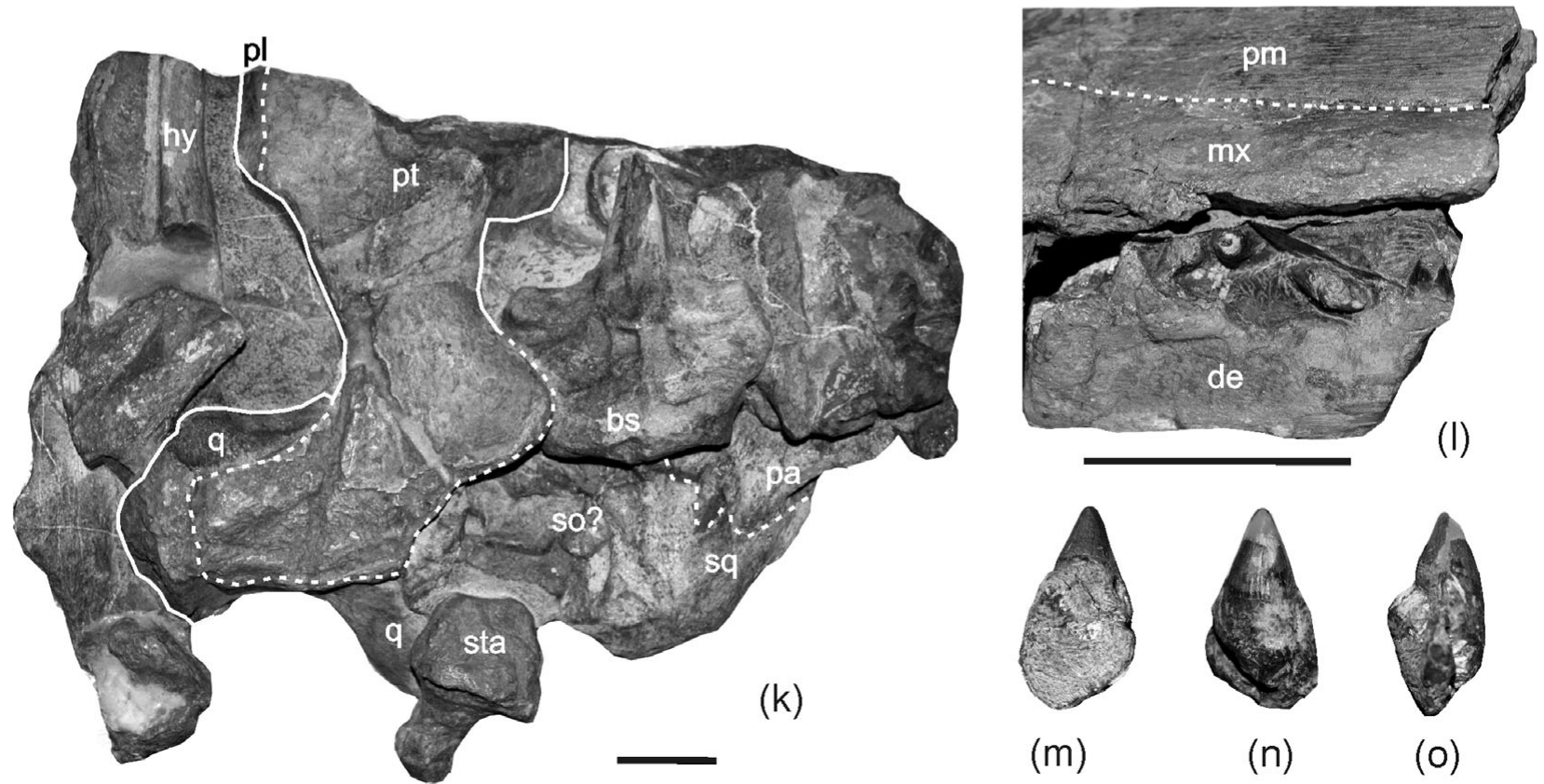

(l)

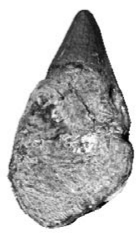

(m)

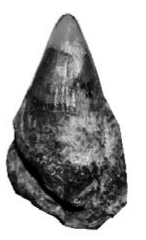

(n)

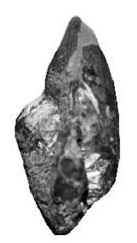

(o)

Figure 2. Mollesaurus periallus (MOZ 2282). (a-d) Basioccipital in posterior (a), anterior (b), lateral (c) and dorsal (d) views; (e, f) articular in lateral (e) and medial (f) views; (g) stapes; (h) opisthotic in medial view; (i, j) exoccipital in medial (i) and posterior (j) views; (k) posterior portion of the skull in ventral view; (l) detail of the alveolar groove; $(\mathrm{m}-\mathrm{o})$ tooth. Anatomical abbreviations: bs basisphenoid; de - dentary; hy - hyomandibular element; $\mathrm{mx}$ - maxilla; pa - parietal; $\mathrm{pl}$ - palatine; pm - premaxilla; $\mathrm{pt}$ - pterygoid; q - quadrate; so? - probable supraoccipital fragment; sq-squamosal; sta - stapes. Scale bars $=5 \mathrm{~cm}(\mathrm{a}-1)$ and $1 \mathrm{~cm}(\mathrm{~m}-\mathrm{o})$.

Skull. Only a small posterior portion of the premaxilla has been preserved. The supranarial process is reduced and its posterior end is rounded, forming the anterior border of the external naris. Ventrally, the premaxilla forms an extensive plate-like subnarial process (Fig. 1a).

The maxilla has a reduced lateral exposure without any conspicuous dorsal process; thus, there is a broad contact between the premaxilla and lacrimal below the external naris. In accordance, the lateral wall of the maxilla is roughly triangular in shape. The preserved portion of the premaxillary process extends anteriorly, passing over the external naris. Posteriorly the maxilla is overlapped by the jugal such that in external view the jugal process of the maxilla is short and ends anterior to the anterior orbital border. Ventrally the maxilla forms a deep alveolar groove within which seven loosely attached teeth have been preserved (Fig. 21). The dental groove bears a relatively thick labial wall. 

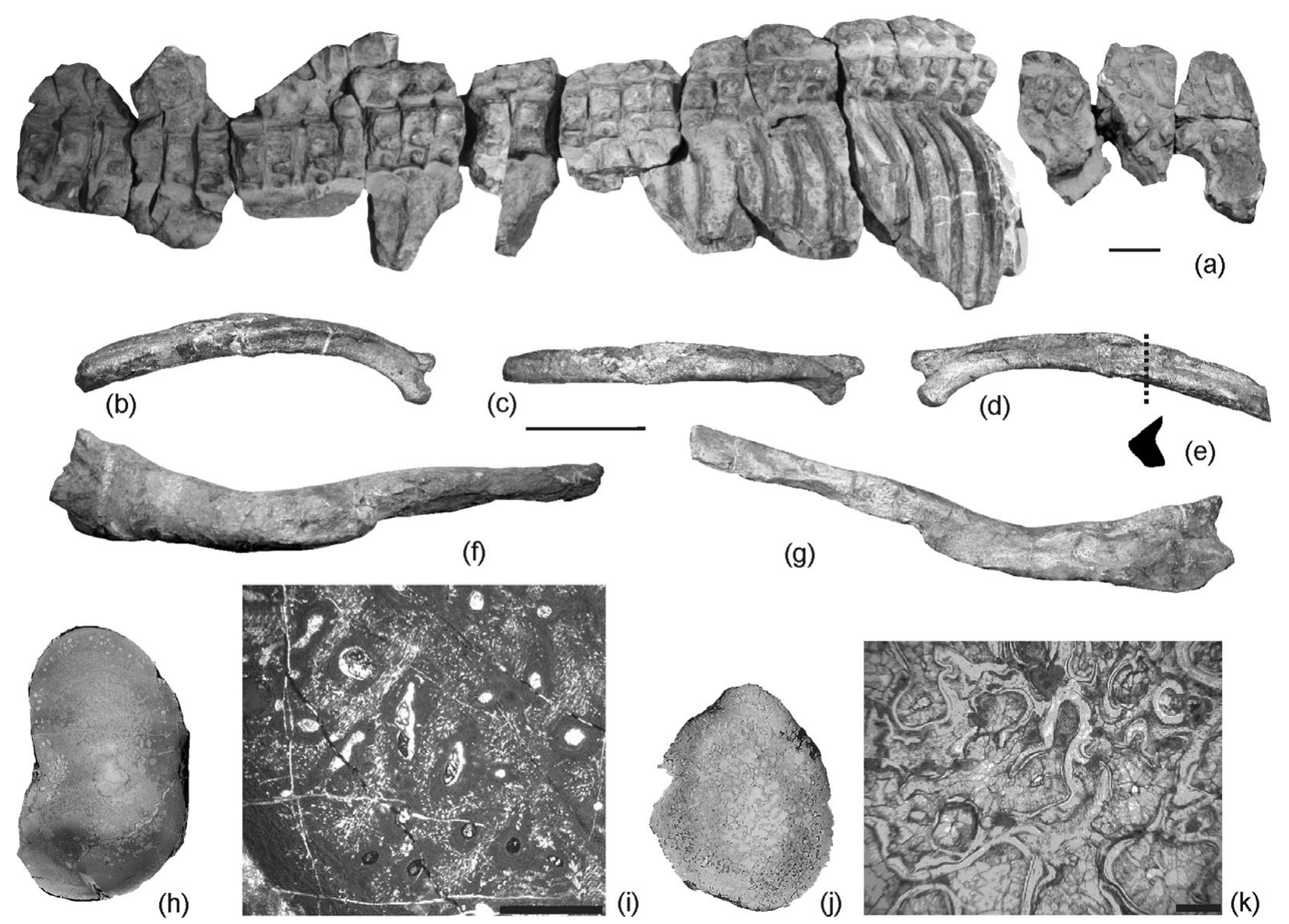

(k)

Figure 3. (a-i) Mollesaurus periallus, MOZ 2282. (a) Vertebral column; (b-d) rib in anterior (b), dorsal (c) and posterior (d) views; (e) schematic transversal section of the rib; (f, g) clavicle, in anterodorsal (f) and posterior (g) views; (h) general view of the transverse section of the rib; (i) peripheral region of the compact cortex of the rib. (j, k) Stenopterygius cayi, MOZ 5803. (j) General view of the transverse section of the rib; (k) peripheral region of the cancellous cortex. Scale bars $=10 \mathrm{~cm}(\mathrm{a}-\mathrm{g}) ; 250 \mu \mathrm{m}(\mathrm{i}, \mathrm{k})$. (h) and (k) not to scale.

Most of the nasal bones have not been preserved except for the posterior portion of the left nasal. Its dorsal and lateral surfaces meet perpendicularly. The posterolateral portion of the nasal is demarked by a blunt crest where it contacts the prefrontal (Fig. 1a, c). Posterodorsally, the nasal ends in an interdigitating suture for its contact with the postfrontal. The anterior lateral surface of the preserved nasal overlaps the lacrimal ventrally. This broad contact would have precluded participation of the prefrontal in the external naris rim.

The lacrimal is a broad element whose most conspicuous feature is a sharp crest running along its posterior margin just anterior to the orbit (Fig. 1a, c). The dorsal end of the crest forms an interdigitating suture with the prefrontal at a level of about half way along the height of the orbit. The ventral portion of the lacrimal is overlapped by the jugal. Dorsally, the lacrimal is overlain by the nasal creating an extensive contact.

The prefrontal forms the anterodorsal margin and roof of the orbit. It is compressed laterally into a supraorbital flange. On the anterior margin, this flange is demarcated by a crescentic groove. The postfrontal is broken and has been reconstructed in plaster. The only exposed portion corresponds to the transverse process contributing to the anterior border of the supratemporal fenestra.

Most of the dorsal surfaces of the parietals are not preserved. Ventrolaterally, however, the remaining component of the parietal is robust and plate-like, forming most of the medial surface of the upper temporal fenestra. Anteriorly it makes a minor contribution to the anteroventral surface of the upper temporal fenestra. Posterolaterally it projects into a stout supratemporal process which articulates with the medial ramus of the supratemporal via a tongue-in-groove suture. The posterior surface of the parietal is deeply excavated for reception of the supraoccipital. The posterior surface of the supratemporal process is concave and deeply pitted. No details of the internal bone surface can be observed.

The anterior portion of the lateral ramus of the supratemporal is partly modelled in plaster. Ventrally the lateral ramus contacts the squamosal through an almost straight suture (Fig. 1b). The median ramus of the supratemporal bears a short transverse shelf; ventrally there is a well-defined ovoid facet 
for the articulation with the paraoccipital of the opisthotic. The ventral ramus of the supratemporal is transversely compressed and bears a posterolateral facet for articulation with the dorsal margin of the quadrate.

The squamosal is an extensive element in the cheek region (Fig. 1a). In lateral view it is roughly square in outline, and extends ventrally up to half the depth of the orbit. The posterodorsal portion of the squamosal is slightly concave for reception of the quadrate (Fig. 1b).

The postorbital is transversely compressed and forms most of the posterior orbital margin. Its lateral surface is overlapped by other cheek elements but the sutures in this region are indistinct (Fig. 1a, b).

The jugal lacks only a fragment of its edge (Fig. 1). Its anterior process ends in an interdigitating suture that overlaps the posterior process of the maxilla anteriorly and the ventral edge of the lacrimal dorsally. The mid-section of the jugal is rod-like and symmetrical in cross-section. The jugal overlies the postorbital posteroventrally. However, the exact extent of this overlap cannot be determined as sutures in this cheek region are not well preserved.

The main body of the quadratojugal cannot be clearly traced; however, its posterior and ventral extremities are well preserved. The quadratojugal has a narrow lateral exposure, and its posterior margin is perpendicularly oriented with the processus quadratus offset from the main body of the bone (Fig. 1b).

The quadrate is a stout element (Fig. 1a, b) with a constricted neck outlined by the lateral embayment of the occipital lamella and the ventromedial portion of the pterygoid lamella (Fig. 2k). In dorsal view the occipital and pterygoid lamellae form an angle of approximately $100^{\circ}$. The dorsal surface of the quadrate is irregular and pitted, indicating the presence of cartilage in vivo. The condyle is partially covered by sediment and mandibular elements. Nonetheless, its exposed area forms an elongated and deeply pitted boss, probably for articulation with the surangular.

The posterior part of the right pterygoid is observable in ventral view (Fig. 2k). Most of the anterior palatal ramus is badly damaged and covered by other crushed elements of the palate. The dorsal wing of the quadrate ramus cannot be observed. However, the pterygoid palatal ramus is broad and separated posterolaterally from the quadrate ramus by an emargination of the subtemporal fenestra laterally and the interpterygoid vacuity medially. The posterior medial edge of the palatal ramus bears a plate-like, dorsomedially directed expansion. The lateral wing of the quadrate ramus is broad, somewhat quadrangular, and its posterior edge is located more posteriorly than the posterior edge of the medial wing.

The anterior and middle portions of both the palatines are crushed and obscured by other bone fragments so they cannot be compellingly defined. The posterior portion of the palatine extends posteriorly as a narrow process along the lateral margin of the palatal ramus of the pterygoid, reaching the anterolateral corner of the subtemporal fenestra (Fig. 2k). This resembles the condition in Temnodontosaurus trigodon, as described by von Huene (1931) fide Maisch \& Matzke (2000).

The basioccipital bears a large condyle, which is not clearly offset from the extracondylar area. The notocordal pit forms a slight concavity above the centre-point. As in all ophthalmosaurians, the extracondylar area is reduced (McGowan \& Motani, 2003) (Fig. 2a). However, this reduction is not extreme and, similar to $O$. icenicus (A. M. Kirton, unpub. Ph.D. thesis, Univ. Newcastle upon Tyne, 1983), the extracondylar area is still evident ventrolaterally as two elongated and concave areas on both sides of the condyle. The dorsal surface of the basioccipital bears oval exoccipital facets separated by a concavity for the foramen magnum (Fig. 2d). The stapedial facet is elongated, slightly concave and separated dorsally from the opisthotic facet (Fig. 2c). The left portion of the anterior surface of the basioccipital has a long rugose basisphenoid facet (Fig. 2b).

The basisphenoid is roughly pentagonal in dorsal view, with the basisphenoid-parabasisphenoid suture possibly demarcated by a low U-shaped crest. The concave basioccipital facet is subdivided by a vertical median groove. A single carotic foramen pierces the centre of the ventral basisphenoid surface. The rodlike basispterygoid processes are laterally directed, forming an almost right-angle with the midline of the basisphenoid body. On the posterior ventral edge of the basispterygoid processes there are two well-defined deep grooves probably for blood vessels and/or the palatine ramus of the facial nerve (A. M. Kirton, unpub. Ph.D. thesis, Univ. Newcastle upon Tyne, 1983). The parasphenoid lacks most of the cultriform process, but was nonetheless clearly keeled ventrally.

The exoccipital (Fig. 2i, j) is triangular in lateral view and has a markedly deflected anterolateral facet for articulation with the supraoccipital.

The opisthotic is characterized by a short, stout and slightly compressed paraoccipital process. This contrasts with the slender paraoccipital processes of $O$. icenicus (A. M. Kirton, unpub. Ph.D. thesis, Univ. Newcastle upon Tyne, 1983) and Acamptonectes (Fischer et al.2012). As in O. icenicus, the posteromedial border is deflected dorsally, forming a convex facet for articulation with the basioccipital (A. M. Kirton, unpub. Ph.D. thesis, Univ. Newcastle upon Tyne, 1983). The surface for articulation with the exoccipital is divided by a groove possibly housing the glossopharyngeal (IX) or the main hyomandibular branch of the facialis (VII) nerve (Kear, 2005). Anteriomedially (dorsal to the medial edge of the basioccipital facet), the opisthotic bears a notch for the lateral wall of the vagus foramen. The opisthotic also displays a well-developed bony projection forming the dorsal exoccipital facet (as in some specimens of $O$. icenicus: A. M. Kirton, unpub. Ph.D. thesis, Univ. Newcastle upon Tyne, 1983). The anteromedial surface of the opisthotic is dominated by impressions of the membraneous labyrinth of the inner ear. These comprise two anteroventrally confluent 
branches forming a V-shape (Fig. 2h). The more posterior branch is deeper and is interpreted as an impression for the posterior vertical semicircular canal. The anterior canal is slightly curved and corresponds to the impression of the horizontal semicircular canal. There is no conspicuous widening at the point of confluence of the two canals for the posterior ampulla. The ventral edge of the opisthotic is notched for passage of the glossopharyngeal nerve (IX) or the main hyomandibular branch of the facialis nerve (VII); as in Acamptonectes and $P$. australis, this notch is more posteriorly placed than in $O$. icenicus (A. M. Kirton, unpub. Ph.D. thesis, Univ. Newcastle upon Tyne, 1983; Kear, 2005; Fischer et al. 2012).

The stapes is a robust element (Fig. 2g). Its lateral head is broad and dominated by the facet for the basioccipital. The shaft is stout and widens slightly laterally.

Two fragments of rod-like elements have been preserved lying on the medial surface of the mandible (Fig. 2k). According to their position and morphology they probably correspond to the branchial horns of the hyoid apparatus.

The mandible is incomplete and sutures among its elements cannot be confidently traced (Fig. 1a). The posterior portion of the mandible has been displaced and a fragment of surangular is exposed within the orbit. The only element that is complete is the articular. This is a compact element resembling that of Ichthyosaurus (see McGowan, 1973, pl. 6d), and differs from that of $O$. icenicus in being higher than long (A. M. Kirton, unpub. Ph.D. thesis, Univ. Newcastle upon Tyne, 1983, fig. 15 and pers. obs.).

Dentition. Seven incomplete teeth have been recovered. They are all small, conical and almost straight (Fig. 21). One tooth was completely removed and prepared; its length equals $20 \mathrm{~mm}$ while the crown height equals $10 \mathrm{~mm}$. The base of the enamel layer is well defined. The crowns bear subtle striations on the labial surface; the lingual surface of the enamel surface is almost smooth (Fig. 2m-o).

Postcranium. The ventral surface of the atlas-axis complex is dominated by a broad ventral keel. In lateral view a thin ridge indicates the suture line between both centra. The discontinuous series of 38 trunk and caudal vertebrae is still covered by rock, leaving their right lateral aspect exposed. As in other Jurassic ichthyosaurs (e.g. Ophthalmosaurus, Aegirosaurus, Caypullisaurus; pers. obs.), the regionalization of the vertebral column is not clear. Although, following the criteria of A. M. Kirton (unpub. Ph.D. thesis, Univ. Newcastle upon Tyne, 1983), 21 centra can be attributed to the anterior trunk region, 14 to the posterior trunk region and 3 to the anterior caudal region (Fig. 3a). The preserved diapophysis in the anterior trunk centra are confluent with the neural arch, and the parapophysis in the most anterior centra placed about halfway down the side of the centrum. The neural arches are similar to $O$. icenicus, manifesting some degree of overlap (A. M. Kirton, unpub. Ph.D. thesis, Univ. Newcastle upon Tyne, 1983).

Ribs from the anterior and posterior trunk and a few caudal ribs have been preserved. One of the ribs from the anterior trunk has been completely removed from the matrix so it could be observed in all views. Distinctively, it bears a sharp dorsal crest on the proximal and medial portion (Fig. 3be); thus, Mollesaurus ribs (Fig. 3e) differ from the eight-shaped cross-section of other thunnosaurians (e.g. Ophthalmosaurus: McGowan \& Motani, 2003; Caypullisaurus: pers. obs.). The bone histology of Mollesaurus' ribs is characterized by a thick, compact cortex (Fig. 3h) (Talevi \& Fernández, 2012).

The right clavicle (Fig. 3e, f) is convex anteriorly and concave posteriorly; like $O$. icenicus (A. M. Kirton, unpub. Ph.D. thesis, Univ. Newcastle upon Tyne, 1983), its medial extremity is digitiform.

\section{4.a. Phylogenetic position of Mollesaurus periallus}

In order to explore the phylogenetic relationships of Mollesaurus, new character scores were added to the dataset of Druckenmiller \& Maxwell (2010) (Table 1). We preferred this matrix because it samples ophthalmosaurian taxa at the species level, and provides a rigorous set of character definitions with scores from first-hand observations. Characters 1, 5, 6, 11 and 25 of Druckenmiller \& Maxwell (2010), originally coded as missing data (?), were modified for Mollesaurus (character definitions in appendix A, Druckenmiller \& Maxwell, 2010, pp. 1052-3). Our analyses used exact parsimony searches in TNT v1.1 (Goloboff, Farris \& Nixon, 2010), with branch support calculated using 500 bootstrap replicates and Bremer decay options. Results generated two most-parsimonious trees of 88 steps (consistency index $=0.648$; retention index $=$ $0.631)$. The general topology did not differ from that of Druckenmiller \& Maxwell's (2010) except that Mollesaurus is recovered as the sister taxon of Aegirosaurus leptospondylus + Ophthalmosaurus icenicus (Fig. 4).

\section{OPHTHALMOSAURIA sensu Motani, 1999 Genus and species indet. Figure 5a}

Material. MLP 92-III-2-1. Fragment of a forefin including the distal portion of the humerus, zeugopial and basipodial elements.

Locality and horizon. Quebrada Remoredo on the western slope of Sierra de Reyes, Mendoza province, Argentina. The ammonoid zone of Puchenquia malarguensis (AalenianBajocian boundary, Riccardi 2008) of the Los Molles Formation.

Remarks. The discovery of MLP 92-III-2-1 is significant for the evolutionary history of ophthalmosaurians because it extends their biochron back $14 \mathrm{Ma}$, from the Callovian to the Aalenian-Bajocian boundary (Fernández, 2003). 
Table 1. Druckenmiller \& Maxwell (2010) data matrix amended with Mollesaurus new information

Cymbospondylus petrinus

Stenopterygius

Ichthyosaurus

Mollesaurus periallus

Brachypterygius extremus

Aegirosaurus leptospondylus

Ophthalmosaurus icenicus

Ophthalmosaurus natans

Arthropterygius chrisorum

Caypullisaurus bonapartei

Maiaspondylus lindoei

Platypterygius americanus

Platypterygius hercynicus

Platypterygius platydactylus

Platypterygius australis

Athabascasaurus bituminous
$0000 ? 0001000001 ? ? 01[01] ? ? ? 20 ? 111000 ? 000000 ? 00 ? 0000 ? ?$ $0[01] 20 ? 0010100101000001 ? 021 ? 00110 ? ? 000110100120010$ ? $0120 ? 00001102[01] ? 0 ? 100000200010100 ? 0002000000[01] 00201$ $1220010 ? ? ? 0 ? ? 00 ? ? ? 00111 ? 1$ ? $01 ? ?$ ?????????? ????????? 0210?10??? ???0?1???0 ?12[01]0???01 $1010102100100 ? ? ? ? ? ?$ [01]220?11011 0?11????????111?1?01 1??0102100 100[12]00?0? $112001101100110000001110010001101100210010010020[01]$ $1020 ? 000010011 ? ? ? 00 ? 1$ ? 10[01]00101 10?100210? 100??????

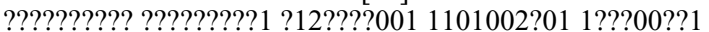
0210??0??1 ?000????0? ??11??1101 10?1002111 110200210 011010???? ?????1???0 1???1??101 101010?101 ????11??0 0111?1???1 ?020?????? 11211??101 10?0012101 ????10??0

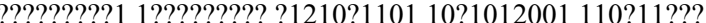
?????????? ?????????? 1?210?1101 10?0002101 ?10?????? $00101100111020111100112101110110110[01] 2101110210210$ 1 ?10110001 0100?????? ??201101?? ?????????????2?????

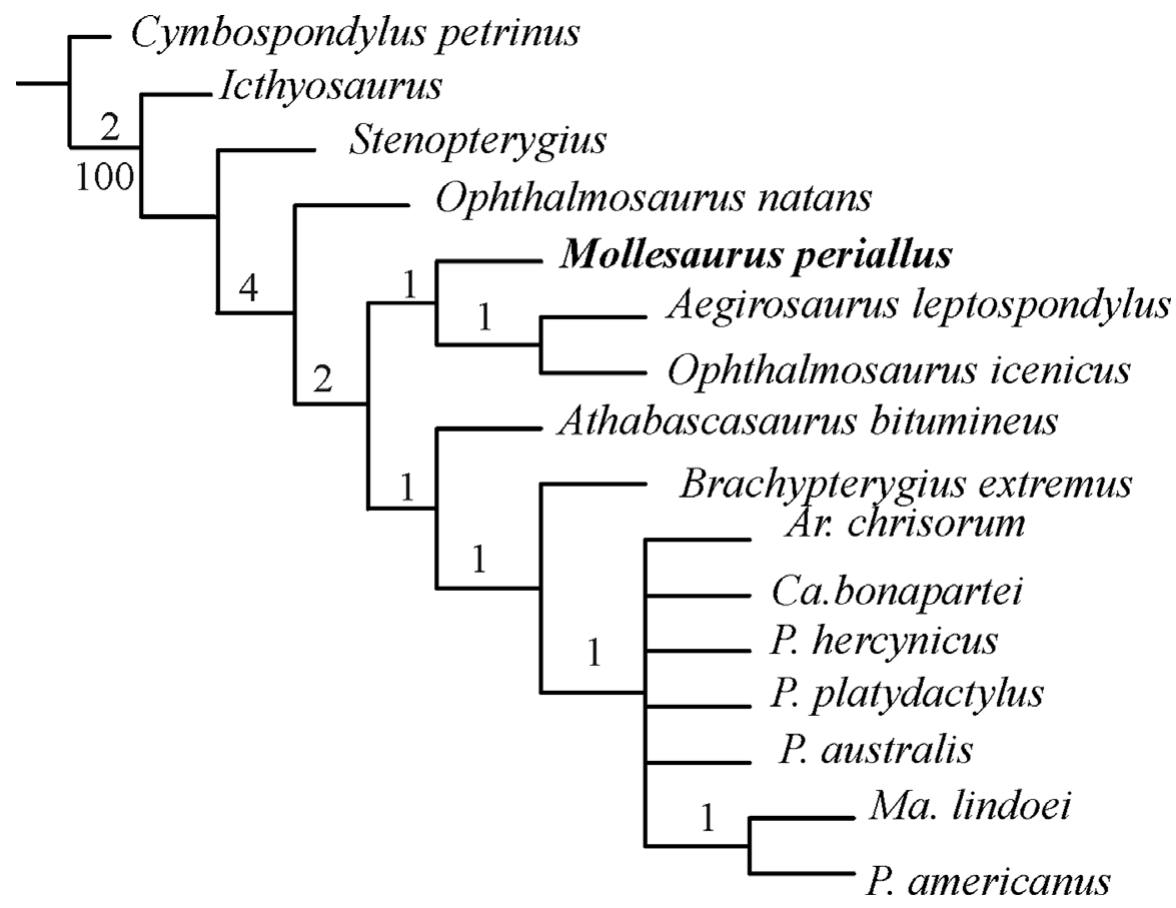

Figure 4. Consensus tree of the two most-parsimonious trees based on the dataset of Druckenmiller \& Maxwell (2010) (tree length $=89$ steps; consistency index $=0.648$; retention index $=0.631$ ). Bootstrap values ( 500 replicates) for clades with greater than $50 \%$ support are given below the branches, and Bremer support values are shown above.

Together with Mollesaurus periallus and Stenopterygius cayi, it documents the co-occurrence of ophthalmosaurian and non-ophthalmosaurian forefin patterns at least during the Aalenain-Bajocian.

Order ICHTHYOSAURIA de Blainville, 1835 Family, genus and species indet

Figure $5 \mathrm{~b}-\mathrm{f}$

1939 Stenopterygius grandis Cabrera, 1939, pp. 48791.

Material. MLP 39-VII-2-2. Fragment of rostrum.

Locality and horizon. Charahuilla creek, Neuquén province, Argentina. Emileia giebeli ammonite zone of the Los Molles Formation, early Bajocian (Westermann \& Riccardi, 1979) cropping out at Charahuilla Creek, Sierra de Chacaico, Neuquén Basin.

Description. The rostrum is robust and preserves fragments of both premaxillae, the anterior portion of both maxillae, the left nasal exposed externally, a fragment of the vomers and a few broken teeth. The maxilla has limited lateral exposure, but contributes to the dental groove. The root portions of 12 teeth are preserved in situ. They are tightly packed and appear to have extended beyond the edge of the dental groove as occurs in Temnodontosaurus platyodon (McGowan \& Motani, 2003).

Remarks. The tooth root morphology and robust rostrum of MLP 39-VII-2-2 resemble Temnodontosaurus and Suevoleviathan. However, its manifest states are not diagnostic (McGowan \& Motani, 2003); thus, Stenopterygius grandis is a nomen dubium. 

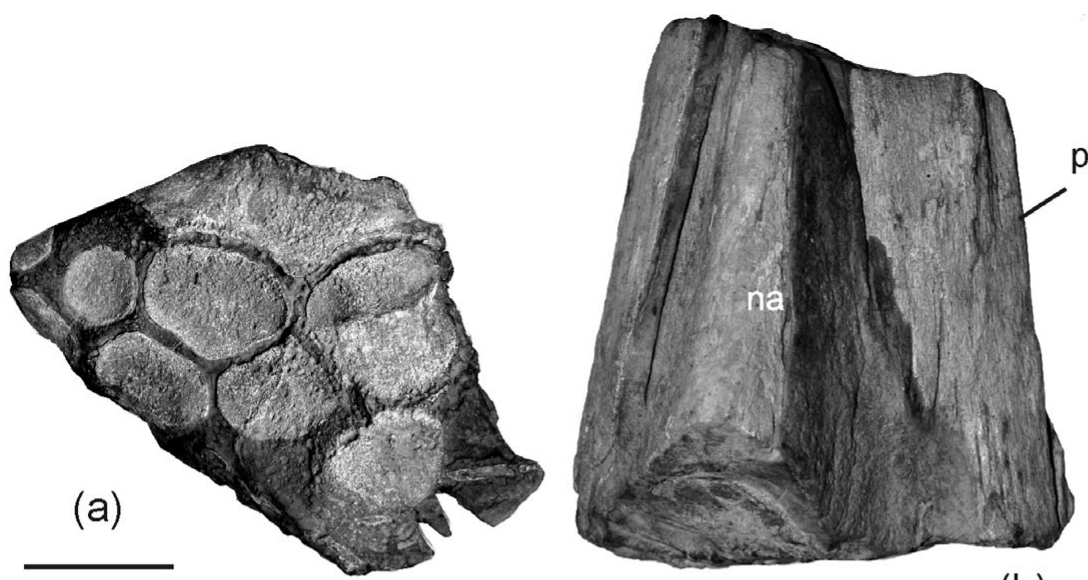

(b)

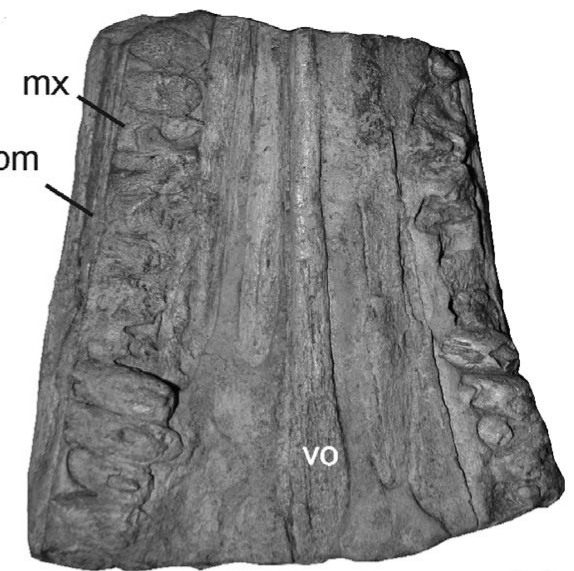

(c)

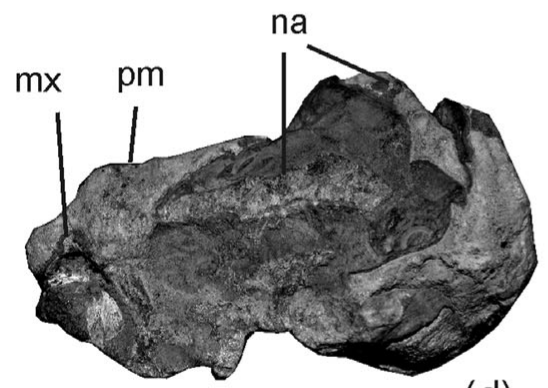

(d)

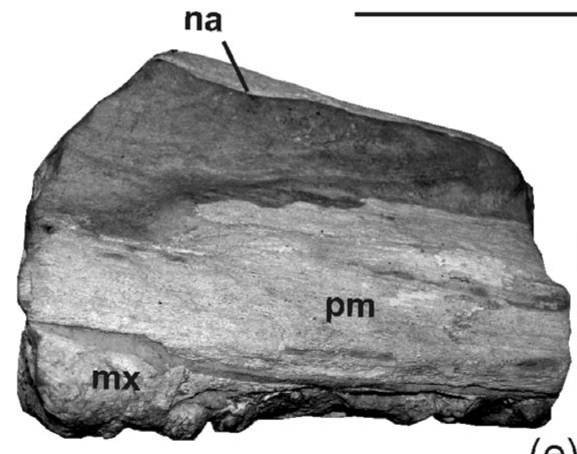

(e)

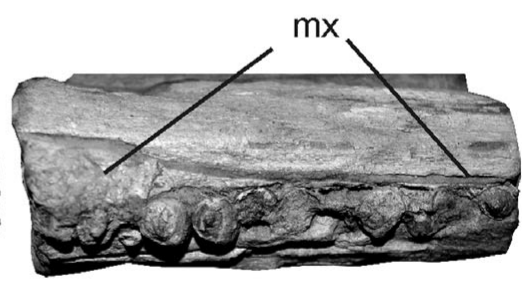

(f)

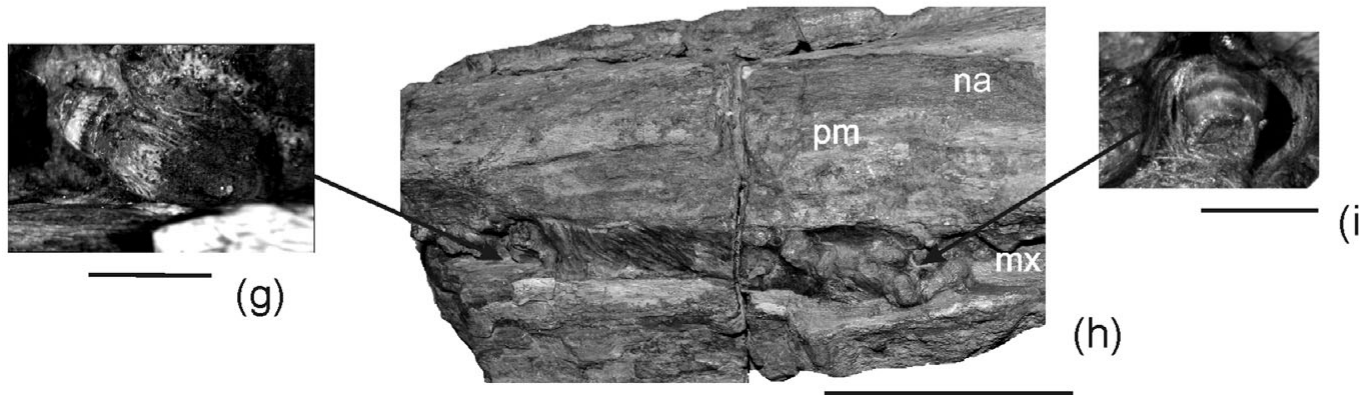

Figure 5. (a) MLP 92-III-2-1. Ophthalmosaurian forefin. (b-f) MLP 39-VII-2-2. Holotype of 'Stenopterygius grandis'. (b) Dorsal view; (c) ventral view; (d) anterior view; (e) lateral view; (f) detail of the anterior extension of the right maxilla. (g-i) MOZ 5803. Holotype of Stenopterygius cayi. (g) and (i) teeth; (h) fragment of the snout. Anatomical abbreviations: na - nasal; mx - maxilla; $\mathrm{pm}$ - premaxilla; vo - vomer. Scale bars $=5 \mathrm{~cm}(\mathrm{a}, \mathrm{f}, \mathrm{h}) ; 10 \mathrm{~cm}(\mathrm{~b}-\mathrm{e})$; and $0.5 \mathrm{~cm}(\mathrm{~g}, \mathrm{i})$.

\section{Discussion}

The Neuquén Basin ophthalmosaurian records and MLP 39-VII-2-2 are significant because, together with Stenopterygius cayi and S. aaleniensis (Maxwell, Fernández \& Schoch, 2012), they document a poorly known period in the evolutionary history of ichthyosaurs: the Aalenian-Bajocian. The presence of definitive ophthalmosaurians (e.g. MLP 92-III-2-1) at the Aalenian-Bajocian boundary indicates that some major advances in the thunnosaurian bauplan were achieved by $170 \mathrm{Ma}$ ago. These subsequently persisted for most of ichthyosaur evolutionary history until the final extinction of the group around $90 \mathrm{Ma}$.

The Patagonian ichthyosaur records are also interesting in terms of palaeodiversity. For example, they show that during the Bajocian the palaeogulf on the southern margins of the Palaeopacific Ocean, represented by the sediments of the Los Molles Formation of the Neuquén Basin, was inhabited by at least three different ichthyosaurian taxa. Although MLP 39-VII2-2 cannot be determined positively at lower taxonomic levels, it can be clearly differentiated from the coeval Mollesaurus periallus and Stenopterygius cayi, both of which have much more gracile dentitions (Figs $2 \mathrm{~m}-\mathrm{O}$, 5c, f, $g, h$ ).

The Patagonian record also provides insights into the ecological diversity of thunnosaurians during the Bajocian. Recent examinations of bone ultrastructure in Mollesaurus have demonstrated that the ribs were stout, with a conspicuously thickened compact cortex (Talevi \& Fernández, 2012). The compactness index of Mollesaurus ribs $(\mathrm{CI}=74 \%$ ) contrasts with the overall cancellous bone rib elements reported in other 
parvipelvians such as Caypullisaurus $(\mathrm{CI}=34.3 \%$; Talevi, Fernández \& Salgado, 2012). A transverse section of rib from Stenopterygius cayi (Fig. 3i, j) similarly displays a cancellous microstructure consistent with the expected pattern amongst advanced ichthyosaurians (Lopuchowycz \& Massare, 2002; Kolb, Sánchez-Villagra \& Scheyer, 2011; Talevi, Fernández \& Salgado, 2012). The different microanatomical osseous specializations of S. cayi and Mollesaurus ribs ('osteoporotic-like' versus bone mass increase) suggest differences in their lifestyle, probably adaptation to slow swimming, in contrast to high-speed manoeuvrability in offshore pelagic habitats (Houssaye, 2013).

Acknowledgements. M. Reguero (MLP) and A. Garrido (MOZ) are thanked for access to collections under their care, and Acosta Burllaile (MLP) for fossil preparations. Financial support was given by CONICET (PIP 0433), ANCyT (PICT0246) and UNLP (N607) of Argentina. TNT v1.1 was made available by the Willi Hennig Society. The manuscript was greatly improved by helpful comments from Dr Benjamin Kear and another anonymous reviewer.

\section{References}

BARDET, N. 1994. Extinction events among Mesozoic marine reptiles. Historical Biology 7, 313-24.

CABRERA, A. 1939. Sobre un Nuevo ictiosaurio del Neuquén. Notas del Museo de La Plata 21, 485-91.

Dal SASso, C. \& PINNA, G. 1996. Besanosaurus leptorhynchus n. gen. n. sp., a new shastasaurid ichthyosaur from the Middle Triassic of Besano (Lombardey, N. Italy). Paleontologia Lombarda 4, 1-23.

De Blainville, H. M. D. 1835. Description de quelques espèces de reptiles de la Californie. Nouvelles Annales du Muséum d'Histoire Naturelle 4, 233-96.

Druckenmiller, P. S., Hurum, J. H., Knutsen, E. M. \& NAKREM, H. A. 2012. Two new ophthalmosaurids (Reptilia: Ichthyosauria) from the Agardhfjellet Formation (Upper Jurassic: Volgian/Tithonian), Svalbard, Norway. Norwegian Journal of Geology 92, 31139.

Druckenmiller, P. S. \& MaXwell, E. E. 2010. A New Lower Cretaceous (Lower Albian) Ichthyosaur Genus from the Clearwater Formation. Canadian Journal of Earth Sciences 1053, 1037-53.

FERNÁNDEZ, A. 1943. La serie Jurásica de la parte central y meridional de la Sierra de Chacai-Co y sus relaciones con los terrenos que la soportan. Ph.D. thesis. Tesis del Museo de La Plata $\mathrm{N}^{\circ} 6$, Universidad Nacional de La Plata, Argentina. Published thesis.

FERNÁNDEZ, M. S. 1994. A new long snouted ichthyosaur from the early Bajocian of Neuquén Basin (Argentina). Ameghiniana 31, 291-7.

FERNÁNDEZ, M. S. 1999. A new ichthyosaur from the Los Molles Formation (Early Bajocian), Neuquén basin, Argentina. Journal of Paleontology 73, 677-81.

FERNÁNDEZ, M. S. 2003. Ophthalmosauria (Ichthyosauria) forefin from the Aalenian-Bajocian boundary of Mendoza province, Argentina. Journal of Vertebrate Paleontology 23, 691-4.

FERNÁNDEZ, M. S. 2007. Ichthyosauria. In Patagonian Mesozoic Reptiles (eds Z. Gasparini, L. Salgado \& R. A. Coria), pp. 271-91. Indiana University Press.
Fernández, M. S., Archuby, F., TAlevi, M. \& Ebner, R. 2005. Ichthyosaurian eyes: paleobiological information content in the sclerotic ring of Caypullisaurus (Ichthyosauria, Ophthalmosauria). Journal of Vertebrate Paleontology 25, 330-7.

Fischer, V., Clément, A., Guiomar, M. \& Godefroit, P. 2011a. The first definite record of a Valanginian ichthyosaur and its implications on the evolution of postLiassic Ichthyosauria. Cretaceous Research 32, 155-63.

FISCHER, V., MAISCH, M. W., NAISH, D., KOSMA, R., LISTON, J., Joger, U., KrÜGer, F. J., PARdo PÉrez, J., TAinsh, J. \& APPleBY, R. M. 2012. New ophthalmosaurid ichthyosaurs from the European Lower Cretaceous demonstrate extensive ichthyosaur survival across the Jurassic-Cretaceous boundary. PLoS ONE 7, 1-23.

Fischer, V., Masure, E., ARKhangelsky, M. S. \& GODEFroIT, P. 2011b. A new Barremian (Early Cretaceous) ichthyosaur from western Russia. Journal of Vertebrate Paleontology 31, 1010-25.

GASPARINI, Z. 1997. A new pliosaur from the Bajocian of the Neuquen Basin, Argentina. Palaeontology 40, 135-47.

GodefroIT, P. 1993. The skull of Stenopterygius longifrons (Owen, 1881). Revue de Paléobiologie 7, 67-84.

GolobofF, P., FARris, J. \& NiXON, K. 2010. T.N.T. 1.1: Tree Analysis Using New Technology. Available at http://www.zmuc.dk/public/phylogeny/TNT/.

HOUSSAYE, A. 2013. Bone histology of aquatic reptiles: what does it tell us about secondary adaptation to an aquatic life? Biological Journal of the Linnean Society 108, 3 21.

KEAR, B. P. 2005. Cranial morphology of Platypterygius longmani Wade, 1990 (Reptilia, Ichthyosauria) from the Lower Cretaceous of Australia. Zoological Journal of the Linnean Society 145, 583-622.

Kolb, C., Sánchez-Villagra, M. R. \& Scheyer, T. M. 2011. The palaeohistology of the basal ichthyosaur Mixosaurus Baur, 1887 (Ichthyopterygia, Mixosauridae) from the Middle Triassic: palaeobiological implications. Comptes Rendus Palevol 10, 403-11.

Lopuchowycz, V. B. \& MASSARE, J. A. 2002. Bone microstructure of a cretaceous ichthyosaur. Paludicola 3, 139-47.

MAISCH, M. W. 2010. Phylogeny, systematics, and origin of the Ichthyosauria - the state of the art. Palaeodiversity 3, 151-214.

MAisch, M. W. \& MATZKE, A. T. 2000. The Ichthyosauria. Stuttgarter Beiträge zur Naturkunde Serie B (Geologie und Paläontologie) 298, 1-159.

MASSARE, J. A. 1987. Tooth morphology and prey preference of Mesozoic marine reptiles. Journal of Vertebrate Paleontology 7, 121-37.

MAXWELL, E. E. 2010. Generic reassignment of an ichthyosaur from the Queen Elizabeth Islands, Northwest Territories, Canada. Journal of Vertebrate Paleontology 30, 403-15.

MaXwell, E. E., Fernández, M. S. \& SchOCH, R. 2012. First diagnostic marine reptile remains from the Aalenian (Middle Jurassic): a new ichthyosaur from southwestern Germany. PLOS ONE 7, e41692.

MAZIN, J.-M. 1982. Affinités et phylogénie des Ichthyopterygia. Geobios, Mémoire spéciale 6, 85-98.

MCGOWAN, C. 1973. The cranial morphology of the Lower Liassic Latipinnate ichthyosaurs of England. Bulletin of the British Museum (Natural History) Geology 24, 1109,9 pls.

MCGowan, C. \& Motani, R. 2003. Part 8 Ichthyopterygia. In Handbook of Paleoherpetology (ed. H. D. Sues). München: Verlag Dr. Friedrich Pfeil. 
Motani, R. 1999. Phylogeny of the Ichthyopterygia. Journal of Vertebrate Paleontology 19, 472-95.

MoTANI, R. 2005. Evolution of fish-shaped reptiles (Reptilia: Ichthyopterygia) in their physical environments and constraints. Annual Review of Earth and Planetary Sciences 33, 395-420.

RICCARDI, A. C. 2008. El Jurásico de la Argentina y sus ammonites. Revista de la Asociación Geológica Argentina 63, 625-43.

SANDER, P. M. 2000. Ichthyosauria: their diversity, distribution, and phylogeny. Paläontologische Zeitschrift 74, $1-35$.

Spalletti, L. A., Gasparini, Z. \& FernándeZ, M. 1994. Facies, ambientes y reptiles marinos de la transición entre las formaciones Los Molles y Lajas (Jurásico Medio), Cuenca Neuquina, Argentina. Acta Geologica Leopoldensia 39, 329-44.
TAleVI, M. \& FernÁndeZ, M. S. 2012. Unexpected skeletal histology of an ichthyosaur from the Middle Jurassic of Patagonia: implications for evolution of bone microstructure among secondary aquatic tetrapods. Naturwissenschaften 99, 241-4.

Talevi, M., Fernández, M. S. \& SAlgado, L. 2012. Variación ontogenética en la histología ósea de Caypullisaurusbonapartei Fernández, 1997 (Ichthyosauria: Ophthalmosauridae). Ameghiniana 49, 38-46.

Thorne, P. M., RutA, M. \& Benton, M. J. 2011. Resetting the evolution of marine reptiles at the Triassic-Jurassic boundary. Proceedings of the National Academy of Sciences of America 108, 8339-44.

Westermann, G. E. G. \& Riccardi, A. C. 1979. Middle Jurassic ammonoid fauna and biochronology of the Argentine-Chilean Andes. Part II: Bajocian Stephanocerataceae. Palaeontographica A 164, 85-188. 